\title{
Letter to the editor regarding "Treatment of non-united femoral neck fracture by a novel subtrochanteric angulation lateral translation valgus osteotomy (SALVA osteotomy)" by Hegazy et al
}

\author{
Tomonori Shigemura ${ }^{1}$ (D) \\ Received: 15 June 2020 / Accepted: 22 June 2020 / Published online: 27 June 2020 \\ (C) SICOT aisbl 2020
}

I read with great interest an article titled "Treatment of nonunited femoral neck fracture by a novel subtrochanteric angulation lateral translation valgus osteotomy (SALVA osteotomy)" by Hegazy et al. [1] published in the June 2020 issue of the journal and would like to congratulate the authors for their study. Although they have touched a highly pertinent topic in a scientific manner, the study has brought an important issue that I would like to communicate with the authors.

Authors developed a novel subtrochanteric valgus angulation with lateral translation osteotomy (SALVA osteotomy) and reported the results of 21 hips that were performed with SALVA osteotomy for neglected or non-united femoral neck fractures. As a result, the pre-operative Harris Hip Score was $14.58 \pm 8.31$, and it improved significantly to $78.68 \pm 19.63$ post-operatively at 24 months $(<0.0001)$. Authors concluded that SALVA osteotomy restores the abductor lever arm and improves the leg length discrepancy. However, pre-operative abductor lever arm was $21.02 \pm 4.07$, and it decreased significantly to $19.12 \pm 2.91$ at post-operative at 24 months $(p<0.0026)$. I think this result is inconsistent with the conclusion. Additionally, there was no significant difference in leg length discrepancy between pre-operative and post-operative at 24 months $(p=0.15)$. I think this result is also inconsistent with the conclusion.
I respectfully appreciate that Hegazy et al. provided me with this important study. Although there were contradictions, it is still an excellent research which made great contribution to the literature. However, addressing these issues should be carried out to make the research more clear and logical.

\section{Compliance with ethical standards}

Conflict of interest The author declares that he/she has no conflict of interest.

\section{Reference}

1. Hegazy M, Basha N, Elbarbary H, Ali EMA, Khalifa AH, Mohamed MT, Diab NM, Zein AB, Abdelazeem AH, Fawaz K, Ahmed AM, Barakat AS (2020) Treatment of non-united femoral neck fracture by a novel subtrochanteric angulation lateral translation valgus osteotomy (SALVA osteotomy). Int Orthop. https://doi.org/10. 1007/s00264-020-04527-8

Publisher's note Springer Nature remains neutral with regard to jurisdictional claims in published maps and institutional affiliations.

Tomonori Shigemura

tshigepon@yahoo.co.jp

1 Department of Orthopaedic Surgery, Teikyo University Chiba Medical Center, 3426-3 Anesaki, Ichihara, Chiba 299-0111, Japan 